\title{
Autenticidad documental y escribanos de Ávila en la Baja Edad Media
}

\author{
Blas Casado Quintanilla *
}

Las cancillerías reales han sido consideradas, y con razón suficiente, como modelo y como espejo en el que podía encontrarse el reflejo de todas las escribanías señoriales, fuera grande o pequeño el rango del "señor» que disponía de una "oficina" para la elaboración y expedición de sus documentos. Las abundantes investigaciones sobre aquéllas ${ }^{1}$ y la escasez de estudios sobre éstas ${ }^{2}$ no hacen sino confirmar la importancia de las primeras en perjuicio de las segundas.

Aparte de éstos, existen otros centros emisores de documentos como son los concejos de las villas y ciudades, lugares en los que hay que reseñar la presencia de los escribanos públicos del número y los escribanos del concejo, a quienes el ejercicio de su oficio les impone otros esquemas bien distintos en el tratamiento de los documentos a los que podían regir en ambientes cancillerescos.

* Universidad a Distancia.

1 Casi todas las cancillerías reales, individualmente o por períodos, han ocupado el tiempo de ilustres investigadores. Aunque no es el lugar indicado, baste recordar el nombre de algunos estudiosos del tema sin ánimo de ser exhaustivos: Filemón Arribas ArRanz, antonio Floriano Cumbreño, Agustín Millares Carlo, luis Sanchez Belda, Francisco Sevillano Colom, María de la Soterraña Martín Postigo, Angel Canellas, Luis núñez, Trench Odena, Santos LaRRagueta, etc.

2 Ya notamos la escasez de estudios sobre cancillerías señoriales en otra ocasión. B. CASADO QUiNTANILLA: "La cancillería y las escribanías de la orden de Calatrava", Anuario de Estudios Medievales, 14, 1984, 73-99. 
Mientas preparábamos la publicación de los documentos medievales que se conservan del concejo abulense ${ }^{3}$ hemos recogido algunas notas que vamos a dar a conocer, no porque sea algo novedoso, sino como contribución al conocimiento de la actividad desarrollada por unos oficiales públicos, los escribanos de una ciudad castellana, que elaboran, signan y leen públicamente documentos en el ámbito de la comunidad de Villa y Tierra donde viven.

\section{LOS DOCUMENTOS}

El concejo de Ávila debió recibir y conserva aún un buen número de diplomas regios durante la época que nos ocupa, a los que tenían acceso los escribanos del concejo y que conocían, sin duda, los escribanos públicos del número de la ciudad. A pesar de ello cuando estos escribanos hacen referencia o inseitan los documentos reales en sus escrituras, dejan constancia imprecisa de los distintos tipos de documentos de aquella cancillería. No encontramos la clasificación conocida de: mandato, albalá, sobrecarta, cédula real, pragmática, carta misiva, etc... De ello, no puede deducirse su desconocimiento, pero puede pensarse que no le concedian mayor importancia a la estructura interna de los diplomas reales, ni consideraban necesario señalar las distinciones jurídicas que las clasificaciones conocidas llevan implícitas.

\subsection{Tipología}

Para los escribanos abuienses se tratan en todo momento de «cartas». Pueden ser cartas de poder, de privilegio, de comisión o carta de compromiso. Cuando aplican a un diploma el concepto de "carta», con o sin los calificativos indicados, tiene la comnotación de ser un documento que ha de ser conocido por el público en general y siempre va seguido del verbo: "vieren». Esta calificación diplomática aparece siempre en el encabezamiento del documento, conformando la cláusula de la notificación, sin per-

${ }^{3}$ A. Barios García, B. Casado Quintanilla, C. Luis lópez, G. Del Ser Quijano: Documentación del Archivo Municipal de Ávila, Institución "Gran Duque de Alba». Ávila 1988. 
juicio de que la volvamos a encontrar de nuevo en el dispositivo, aunque con otra significación bien distinta a la señalada. Esta "carta" destinada al conocimiento público, puede haber sido preparada y expedida por la cancillería real, por el concejo, por el titular de un señorío o por otra autoridad, pero el destinatario último es el público en general.

Cuando el escribano del concejo o el escribano público del número de la ciudad levantan acta de una reunión del concejo, adoptan una forma literaria semejante a la de las crónicas de la época; no aparecen el calificativo de «carta» ni el verbo «vieren», aunque incorporan todos los componentes jurídicos exigidos por la normativa: datación inicial completa (día, mes, año y lugar), los testigos y la suscripción con su signo. Se trata de documentos de carácter administrativo que conforman un grupo documental distinto del anterior, a la vez que señala la presencia de otra dimensión del quehacer de estos escribanos.

Podíamos detenernos en señalar otros tipos de documentos no ligados directamente a la actividad concejil. Nos referimos a los típicamente notariales, de negocios inter vivos o mortis causa, y a los de carácter judicial. El tratamiento de éstos nos desviaria del objetivo que nos hemos marcado para esta ocasión, aunque no implica minusvalorar su importancia dentro del conjunto documental que hemos tenido ocasión de conocer.

\subsection{Autenticidad}

El día 9 de febrero de 1274 el concejo de Ávila autoriza al concejo de La Adrada, aldea de su Comunidad y Tierra, a realizar roturaciones en el puerto de Avellaneda; en la cláusula de validación del documento se dice: «para que la carta fuere más firme e más cierta que no venga en dubda, nos el concejo de Ávila mandamos a Gómez Nuño, escrivano mayor del concejo, que pusiese el sello del concejo en esta carta en testimonio» ${ }^{4}$.

El día 30 de octubre del año siguiente cuatro caballeros abulenses, con poderes del concejo de Ávila, realizan la demarcación de una dehesa

${ }^{4}$ Archivo Municipal de Ávila. (En adelante AMA). Sección fincas y bienes. leg. 1, fol. 1. 
para su aprovechamiento a favor del concejo de Hoyo, aldea de la Tierra de Ávila. Estos caballeros hacen notar igualmente que: «porque esta carta sea más firme e más valedera... pusimos en ella nuestros seellos pendientes para testimonio ${ }^{5}$.

Estas cláusulas de validación van incorporadas en los dos documentos más antiguos entre los conservados pertenecientes al concejo de Ávila. En ambos casos observamos que el medio de validación utilizado es el sello y no las suscripciones de los escribanos $u$ otras autoridades o personas que sin duda alguna intervinieron en la elaboración de los mismos.

En el primero de los casos vemos cómo aunque el concejo tuviera «escribano mayor», su firma, a tenor de lo que hemos leído, tenía menos valor que el sello puesto en la carta del concejo. Podemos pensar que el concejo quiere dejar constancia de que el contenido jurídico del documento se apoya en su autoridad, que la acción documentada se realiza mediante una decisión voluntaria del propietario, del concejo. Pero también podría pensarse en una razones netamente circunstanciales a la luz del ejemplo siguiente.

En el segundo de los documentos, los cuatro caballeros abulenses, aunque obraban con poderes del concejo, no se nos indica que fueran del concejo, no validan el documento con el sello del concejo sino con el suyo propio, y no se señala la presencia del escribano del concejo. Estos caballeros, aparte de testimoniar mediante la aposición de su sello, que ellos realizaron la acción de la entrega de la dehesa al concejo del Hoyo, desde nuestra óptica hacen público el gran desarrollo que alcanzó el uso del sello durante la segunda mitad del siglo XIII, como medio de suscripción de las actas ${ }^{6}$.

Casi un siglo después, el día 15 de mayo de 1347, "los omes buenos del concejo de dicha aldea del Hoyo" se vieron en la necesidad de

${ }^{5}$ Archivo Histórico Provincial de Ávila. (En adelante AHP). Avila. Sección Ayuntamiento. Caja 27. leg. 1, no. 10, fol. 8.

${ }^{6}$ Para no extendernos en anotaciones bibliográficas sobre sigilografía indicaremos algunas obras de reciente aparición. M. PASTOUREAU: "Les sceaux», en Typologie des sources du Moyen age occidental, 36,1981, Tournhout. Bélgica. A. Riesco TeRRERO: "ll sigillo nella storia della civiltá», Archivio Segreto Vaticano, Mostra documentaria 19 febrero-18 de marzo. 1985. Actas del 1er. Coloquio de Sigilografía, Madrid 1987. (En prensa). F. MeNÉNDEZ-PIDAL DE NAvASCUES: Apuntes de Sigilografía Española. Institución «Marqués de Santillana». Guadalajara 1988. 
justificar la propiedad de la dehesa señalada ante el alcalde entregador de la mesta, Garci Fernández Melgar; éste para acreditar su condición de alcalde «fizo leer una carta, seellada con un seello redondo en que avia figura de un escudo e en el escudo figura de una cruz en que avia figuras de aspas e en derredor de la cruz figura de cuatro lobos e las letras de derredor del syello non se podía leer, en la qual estaba escripto

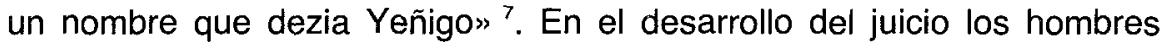
buenos del Hoyo presentaron aquel documento dado por los cuatro caballeros abulenses ya mencionados. Para el escribano del acto se trata de «una carta escripta en pergamino de cuero e seellada con quatro sellos colorados en filos de lino tintos de vermejos, e los sellos heran tan biejos que se non podian esmerar las figuras dellos nin las letras dellos non se podían leer" ${ }^{8}$. A la postre estos sellos son para este escribano el único signo de autenticidad documental y no se hace mención alguna a qualquier otro elemento del documento que pudiera servir de apoyo para acreditar su carácter de original y de auténtico. Todo ello adquiere mayor importancia si consideramos que el escribano en cuestión era muy minucioso, como hemos visto, y un tanto desconfiado si nos atenemos a lo que se dice en otra parte de este documento: «el dicho alcalde mostró e fizo leer un traslado de una carta de nuestro señor el rey, sygnada del sygno de Sancho Fernández, escrivano que se diz de la dicha mesta» ${ }^{9}$. Desconfía el escribano Gonçalo Sánchez de la veradicad del escribano que realizó el traslado del documento regio, pero al mismo tiempo la suscripción que aparece en este traslado es el único elemento de autenticidad documental que se aporta sin que se indique si se han examinado otros extremos de los documentos.

En esta misma línea judicial, pero con un valor bien distinto para nosotros, el día 22 de diciembre de 1356 unos caballeros de Ávila presentaron un privilegio real ante un alcalde $y$ en presencia de Vicente Fernández y Alfonso Méndez, escribanos públicos por el rey en la dicha ciudad. El privilegio "era escripto en pergamino de cuero e seelado con sello de plomo colgado, e rodado de una rueda grande fecha de colores bermejos e verdes e prietos, e en medio de la dicha rueda estavan fechas figuras e ymagenes de leones e de castillos" ${ }^{10}$. Acostumbrados estos escribanos a ver los sellos de plomo o de cera pendientes, que-

\footnotetext{
${ }^{7}$ AHP. Ávila. Sección Ayuntamiento. caja 27, leg. 1, no. 6A, fol. 1-4.

8 Ibidem.

9 Ibidem.

10 AMA. Sección Históricos. leg. 2, no. 14, fols. 2-11.
} 
daron gratamente sorprendidos y hasta cautivados por el signo rodado que es el único que describen con detalle, pero tampoco hacen mención alguna del gran número de suscripciones que acompañan a la rueda.

Estos caballeros demandaban del alcalde su autorización para que los escribanos registraran en sus libros este privilegio, porque temían poder perder el original que mostraban; también pedian que se les diesen luego sendas copias autorizadas. El escribano había leído públicamente el pergamino por mandato del alcalde y a la hora de levantar acta sólo se había detenido en que era un pergamino de cuero, que portaba el sello de plomo y en la descripción de la rueda, pero el alcalde "cató y exsaminó el dicho privilegio e fallolo como complía e non falló roto nin rasgado, nin raydo, nin hemendado, nin sepulcado, nin interlineado nin dudoso en algun lugar" ". Podíamos pensar que el alcalde era un experto en determinar la autenticidad documental, después de que hemos visto que los escribanos no se detenían en mirar con tanto detenimiento si el documento estaba rasgado, raído, enmendado, interlineado o dudoso en algún extremo; de hecho es la primera vez que observamos un análisis tan minucioso de la autenticidad y además puesto en boca de un alcalde o al menos por expresa indicación de un alcalde porque a nuestro juicio contó con la colaboración de un grupo de expertos antes de dictar sentencia favorable.

En todos los documentos se destaca la presencia de unos testigos en el momento del acto escriturado; unas veces se les señalaba con la expresión "testigos que fueron presentes", lo que en numerosas ocasiones podiamos traducir a nuestro lenguaje como ocasionales o necesarios para la validad jurídica del acto y otras con las palabras «testigos que fueron rogados" a los que nosotros denominaríamos como llamados expresamente para presenciar el acto. En esta ocasión se dice: «testigos rogados que fueron presentes a esto que dicho es: don Yagüe. fijo de Domingo Miguel, e Alfonso Fernández, escrivano público, e Alvar Martínez, fijo de Sancho Martínez, e Luys Fernández, fijo de Juan Pérez, e Gonzalo Alfonso, fijo de Gregorio Martínez, notarios todos de Ávila» ${ }^{12}$. La calidad de estos testigos, unida a la presencia de los otros dos escribanos ya indicados más arriba, nos autoriza a pensar que el veredicto sobre la autenticidad del documento fue realizado a partir de la valoración que hicieran los escribanos presentes y los notarios llamados a tal efecto

11 Ibidem

12 Ibidem. 
y proclamado por el alcalde como autoridad judicial. Se trata, en definitiva, de poner de manifiesto en qué aspectos se basaban la valoración de autenticidad documental para los escribanos de Avila a mediados del siglo XIV. El documento original presentado tiene ya un siglo. El criterio de autenticidad se queda en el examen de unos caracteres externos; no se detiene en los caracteres internos en ningún momento.

Mediado el siglo xv, día 21 de septiembre de 1453, nos encontramos con otro documento cuyo contenido, para nuestro objetivo en este trabajo, se asemeja al anterior, aunque con una variable que creemos necesario destacar. Los vecinos del Hoyo demanda del corregidor abulense y en presencia del escribano Ferrand González de Arévalo que la sentencia favorable dada por el alcalde de la mesta Garcçi Fernández Melgar, como vimos más arriba, sea incorporada a los libros del registro del escribano público de Ávila. El corregidor «tomó la dicha escriptura oreginal en sus manos e católa e dixo que por quanto la fallava sana e non rota nin chancellada nin en parte alguna sospechosa" ${ }^{13}$ daba su licencia para pasarla al registro del escribano. Pero si el caso anterior habíamos visto cómo los testigos, todos ellos escribanos abulenses y especialmente llamados para el acto, pudieron haber actuado como expertos en discernir la autenticidad documental, en esta ocasión los testigos "que fueron presentes a esto... (eran) vezinos de la dicha çibdad de Ávila» sin que se mencione cualidad alguna especial, a no ser que uno de ellos erá "escudero del dicho señor corregidor». En cualquier caso el análisis sobre la autenticidad documental es en todo similar al que hemos visto con anterioridad, aunque exista una distancia cronológica importante entre ambas acciones.

Veinte años más tarde, el dia 26 de febrero de 1474, el escribano público Ferrand González de Ávila, leyó ante el corregidor de esta ciudad una carta del rey "firmada de su nombre e seellada con su seello de çera colorada en las espaldas e referendada de Garçia Fernández de Alcalá, su secretario, e dada con acuerdo de los del su consejo" ${ }^{14}$. Se ha producido un cambio sustancial. Ya no importan sólo el sello y la firma reales; este escribano llama la atención sobre algunos aspectos nuevos: el refrendo del secretario y el acuerdo del consejo reales. No obstante la imnovación, siguen centrándose en la cláusula de validación el criterio de autenticidad documental, aunque recogiendo elementos que ya existían

${ }^{13}$ AHP. Ávila. Sección Ayuntamiento. Caja 27, leg. 1, fals. 1-5.

${ }^{14}$ AHP. Ávila. Sección Ayuntamiento. Caja 27, leg. 1, fols. 8-17. 
anteriormente en los documentos reales y que no eran mencionados por los escribanos abulenses.

En el mes de noviembre de este mismo año, Fernando Sánchez de Pareja, escribano público y del concejo de Ávila, leyó ante este concejo una carta de la princesa Isabel "escripta en papel e firmada de su nombre, e seellada con su seello de cera colorada en las espaldas, e en las espaldas della señalada de çiertas señales» y más adelante añadirá: «e en las espaldas de la dicha carta esta escripto lo que sigue: registrada, Diego Sánchez. chanceller» ${ }^{15}$. Muy lentamente se van incorporando todos los elementos de la cláusula de validación de los documentos reales pero en ningún momento nos encontramos con un estudio de los elementos internos para dirimir sobre la autenticidad del documento.

\section{LOS ESCRIBANOS}

Omitiremos hacer una relación completa de todos los escribanos que signan los documentos y nos limitaremos a señalar algunos aspectos que implican cambios importantes entre aquellos oficiales.

El día 9 de febrero de 1274 nos encontramos por primera vez con la figura del "escrivano mayor del concejo» en un contexto que apoyaría la hipótesis de que era el depositario del sello del concejo ${ }^{16}$. A partir de esta fecha no se vuelve a hacer mención del escribano mayor del concejo. Se podía añadir que la presencia de un escribano mayor, indirectamente, anuncia la existencia de otro escribano del concejo.

Desde la fecha indicada, son los escribanos públicos «por el dicho señor rey» o «a la merçed del dicho señor rey", los que escrituran los asuntos del concejo de Ávila, pero notamos la presencia de un solo escribano.

15 AMA. Sección Históricos. Leg.1, sin clasificar, 3 folios.

${ }^{16}$ AMA. Ávila. Sección de Fincas y Bienes. Leg. 1, no. 1, fol. 1-1vo. «E porque esta carta fuere más firme e más cierta, que no venga en dubda, nos el conçejo de Ávila mandamos a Gómez Nuño, scrivano mayor del conçejo que pusiese el sello del conçejo en esta carta, en testimonio". 
A partir de septiembre de 1453 aparecen dos escribanos ejerciendo su oficio para dejar constancia escrita de las actividades concejiles, en los más variados aspectos documentales. El día 30 de junio de 1460, Juan Nuñez de Ávila, quien ya había ejercido de escribano del concejo, y Pero Gonzalez de Ávila, dicen ser «Escrivanos públicos de la dicha çibdad por nuestro señor el rey, e escrivanos de los fechos del conçejo» ${ }^{17}$. ¿Por quién son escribanos del concejo? No hemos encontrado noticias para una respuesta satisfactoria.

Esta suscripción permanece con idéntica formulación, aunque cambian las personas, hasta el día 11 de agosto de 1474, fecha en que Ferrand Sánchez de Pareja suscribe como «escrivano público de la dicha çibdad de Ávila a merçed de nuestra señora la princesa (Isabel, la Católica), e escrivano público de los fechos del conçejo de la dicha çibdad» "18; aparece en compañía de otro escribano público y del concejo, que no indica el origen de su nombramiento. La presencia de la princesa Isabel en la suscripción del escribano público abre una nueva perspectiva, como veremos más adelante.

\subsection{Variaciones en el ejercicio del oficio de escribano}

La lectura de los documentos que hemos estudiado con anterioridad nos autorizaba a pensar que los escribanos no podían ser considerados sólo bajo el prisma de notorios, entendiendo por este calificativo, lo que hoy cae dentro del campo de acción de los fedatarios públicos, que sería el campo de actuación en la esfera jurídico privada por motivo de cualquier negocio intervivos o mortis causa que implica mutaciones en el patrimonio o en el estado de las personas. Pero esta fe pública otorgada por los escribanos públicos de los que estamos tratando, tal como lo delatan los documentos y lo recogen las ordenanzas se proyecta en diversas vías.

Ya hemos señalado el primero. Otras veces en el campo de lo jurisdiccional, certificando aquello que tuvo lugar en un procedimiento en el

17 AHP. Ávila Sección Ayuntamiento. Caja 23, no. 12, fols. 1-9. Cfr. E. Corral García: El escribano del concejo en la Corona de Castilla (siglos XI al xVII), Ayuntamiento de Burgos. Burgos 1987.

${ }_{18}$ AMA. Sección Históricos. Leg. 1, fol. 1. Tampoco en esta ocasión se señala a quién deben el nombramiento como escribanos del concejo. 
que se dictó lo que era de Derecho en conflicto de intereses; es decir la fe pública judicial. Pero también le corresponde al escribano público, especialmente si actúa de escribano del concejo, dar fe pública de situaciones y actos administrativos. Por estas razones podemos suscribir las acertadas palabras de Pérez-Prendes: «El hecho de estar distribuidas las competencias de otorgar estas formas de fe pública entre agentes distintos, como son los notarios, los secretarios judiciales y los secretarios generales de órganos colegiados, no puede ni debe hacer olvidar cómo su íntima y unitaria génesis se encuentra en buena medida resumida en la figura del escribano del concejo ${ }^{19}$, especialmente cuando, como es nuestro caso, al mismo tiempo se titula escribano público de número y del concejo, añadimos nosotros. Como escribano público podía dar la fe pública del notario o actuar en los procesos judiciales y como escribano público y del concejo podía dar fe pública de los actos administrativos que se le encomendaran y a las que se refieren en muy diversas ocasiones las ordenanzas abulenses, sin excluir los otros dos aspectos ya que siempre se autocalifican de «escribanos públicos y del concejo".

\subsection{Las Ordenanzas de Ávila}

Hasta el siglo xill los Fueros y los Privilegios reales eran la normativa común para la organización de la vida local en muchas villas y ciudades. Estos fueros y privilegios han sido considerados como las primeras formas de derecho local existente en la historia castellano-leonesa ${ }^{20}$. Desde el último tercio del siglo xIII la insuficiencia o inadecuación de los Fueros se empezó a suplir mediante la promulgación de Ordenanzas Locales. Éstas regulan los procedimientos y ámbitos de actuación de las autoridades locales, la forma de nombrarlas o de elegirlas y la organización de

19 J. M. Perez-Prendes en el Prólogo a la obra de E. Corral Garcia: El escribano del concejo en la corona de Castilla (siglos XI al XVII), Madrid 1987, pág. IX.

A. García UleCia: «El papel de los corredores y escribanos en el cobro de las alcabalas". Historia, Instituciones, Documentos, 13, 1986, 89-110. Donde se presenta a los escribanos sevillanos de finales del siglo $x v$ como oficiales muy destacados en el cobro y recaudación de las alcabalas y se indican determinadas fórmulas de cobro de sus derechos por esta actividad.

${ }_{20} \mathrm{~J}$. LALINDE ABadía: Iniciación histórica al Derecho español. Barcelona 1987; J. M. Pérez Prendes: Curso de Historia del Derecho Español. Madrid 1987. 
los aspectos más variados de la actividad económica agraria, artesanal o mercantil, así como la fiscalidad municipal ${ }^{21}$.

La potestad para emitir estas ordenanzas correspondía a la Corona, a los señores en sus señoríos o a los municipios en sus ámbitos de actuación de la Comunidad de Villa y Tierra. No vamos a entrar en el proceso de elaboración de las Ordenanzas de Ávila; solamente nos referiremos a los capítulos en los que se hace referencia a los escribanos que es nuestro cometido. Antes indicaremos que el Marqués de Foronda publicó ${ }^{22}$ los dos textos que se conservan de este ordenamiento: el original muy mutilado de 1485 y otro en un acta notarial de 1771 .

\subsubsection{Los derechos que debían cobrar los escribanos públicos}

En el texto original el capítulo sobre escribanos dice así: «Otrossi que qualquier escriuano público de la dicha cibdad de Ávila o otro qualquier por ante quien pasaren qualquier escrituras que sean pagadas $o$ dadas a prendar, que sean vista por el dicho corregidor o alcalde e que sean tasadas segun ordenamiento". La copia notarial recoge la "Hordenanza sobre los derechos que han de llevar los escriuanos de número de Ávila» detallando las tasas correspondientes a cada tipo de documento: compraventa, donación, testamentos, procuraciones, cartas de tutoria, cartas de inventario, cartas de embargo, cartas de compromiso, cartas de testimonios o cualquier otra escritura asimilable a las citadas. Continúa con escrituras relacionadas con temas judiciales, con escrituras de remates y pregones.

También existe una «Hordenanza sobre los escriuanos que no son del número de la ciudad de Ávila". En qualquier caso, fueran escribanos públicos del número de la ciudad o del concejo, este organismo regulaba su actividad y fijaba las tasas que podían cobrar por sus actuaciones en todos

24 M. A. Laredo Quesada e I. Galán Parra: "Las ordenanzas locales en la corona de Castilla como fuente histórica y tema de investigación (siglos XIII al XVIII), Revista de Estudios de la Vida Local, 217 Madrid 1983, 85-108. Hacen un inventario de las ordenanzas municipales estudiadas hasta la fecha e incorporan una relación de los temas a los que suelen referirse estos ordenamientos.

${ }^{22}$ Marqués de ForONDA: “Ordenanzas de Ávila», BRAH, LXXI, 1917, 381-520 y LXXII, $1918,25-326$. 
los tipos de escrituras que pasaren ante ellos ${ }^{23}$. Se recogen, también, las multas correspondientes en caso de infracción de la normativa.

En contrapartida a esta regulación concejil, los escribanos públicos abulenses estaban organizados en un cabildo o asociación para la defensa de sus intereses tal como se recoge en las propias ordenanzas y desde el mismo ejercían, al menos en una ocasión ejercieron, la presión suficiente sobre el concejo como para conseguir ciertas mejoras en las tasas fijadas en las Ordenanzas.

El día 3 de febrero de 1488 «estando el conçejo, justicia, regidores, caualleros, escuderos de la dicha cibdad de Ávila ayuntados a su concçejo... e estando ay en el dicho conçejo el honrrado cauallero Alonso Puertocarrero, corregidor... e el bachiller Pedro de Salynas e Andrés Moreno, sus alcaldes, e Alonso de Ávila e Sancho de Bullón e Francisco de Henao, que son de los catorce regidores... e el bachiller Juán Dávila, letrado del dicho conçejo... e estando ay presentes Juán de Arévalo e

${ }^{23}$ Marqués de ForondA: "Ordenanzas de Ávila", BRAH, LXXII, 1918,318 y ss. Sería muy prolijo reproducir aquí toda la "Hordenanza" que hace referencia a este asunto por ello nos limitaremos a reproducir algunos de sus apartados: «de toda carta de venta o renta o compra de donaçión o troque o cambio o contrato de empeños e emprestidos que sean de la quantía de mill maravedies e dende, que se lleue de cada uno diez maravedies e de quantía de mill maravedies fasta en veinte mill maravedies, veinte maravedies e de veinte mill maravedies arriba en qualquiera quantía que sea treinta maravedies; e si estas cosas fueren del concejo e de aljamas e de cofradias e de hermandades que sean estas quantías dobladas según la calidad e cantidad e contrato e non más; e si fueren fechas en almonedas e rematados los bienes que se pague doblado como de concejo o aljama en la forma susodicha; e si escripturas se oiorgaren e non sacaren signadas que se lleuen la mitad de las quantías susodichas".

En lo referente a autos judiciales: «de cada mandamiento de prender e soltar, dos maravedies. De sentencia interlocutoria, dos maravedies, e si fuere sobre causa criminal, quatro maravedies". Por "remates y pregones»: «Hordenamos e mandamos que ninguno ni alguno de los escriuanos del número de esta çibdad non sean osados de dar liçençia a ningunas personas para que vaian a executar ni executasen los derechos suios por su autoridad salvo que vayan tasados e moderados según la forma susodicha por nuestros escriuanos del concejo o por uno de ellos e por un alcalde e firmado de su nombre esto en los autos judiciales e si lo contrario ficçieren que caian en pena los escriuanos de tresçientos maravedies». Por esta última ordenanza y otros artículos que aparecen a lo largo de otros artículos de las mismas, observamos cómo el control de los escribanos públicos del número, en gran medida, recaía sobre los escribanos del concejo, aunque las ordenanzas fueran dadas por el concejo, reconociendo este organismo, por tanto, un papel muy destacado a los escribanos del propio concejo; de forma que, como veremos, tenían el mismo salario que los regidores y los mayordomos. 
Juán Aluarez e Francisco Rodriguez e Pero Xuarez, escriuanos públicos del número de la dicha cibdad ${ }^{24}$.

Los escribanos públicos de Avila demandaban del concejo una subida en las tarifas de las escrituras que pasaran ante ellos, porque las tasas fijadas en las ordenanzas hechas públicas un año antes «todos los dichos escriuanos se auian agrauiado diciendo aver sido en su perjuicio e de los dichos sus oficios» ${ }^{25}$. Los del concejo parece que lo habían hablado durante largo tiempo sin que supieran bien qué respuesta dar a los escribanos públicos. Se habían decidido por poner el asunto en manos del «dicho bachiller Juán Dáuila, letrado del dicho conçejo para que diese su parecer en ello» ${ }^{26}$. El juicio del letrado debió ser favorable a la demanda de los escribanos y el concejo accedió a subir las tasas en varios de los tipos de escritura, aunque no en todos.

Las Ordenanzas agrupan la actividad de los escribanos en tres capítulos: la que podíamos denominar, según se señaló más arriba, negocios intervivos o mortis causa, asuntos judiciales y lo que se llama en la misma normativa "remates y pregones". La negociación entre el concejo y el cabildo de los escribanos da un resultado muy variado. De los ocho artículos que recoge el primero de los grupos mencionados, se respetan seis y dos se cambian a favor de los escribanos: el referente a los testamentos y el de los "testimonios que se tomaren contra juezes o contra otras qualesquier personas». En el capítulo de «auto judiciales» de los dieciocho artículos que contiene, sólo se mantienen cinco, mientras que en el resto se duplican o triplican los derechos de los escribanos públicos. Queremos destacar un artículo. Se dice en las ordenanzas iniciales: "de las tiras de lo procesado que se dieren por apelación o sin ellas que se pague al escribano de cada una tira en que aya cuatro partes, dos maravedies" 27 ; mientras que en el acuerdo se dice: "de cada tira de lo procesado que pase como está en la hordenança syn que aya de contar renglones ni partes ${ }^{28}$. Conocemos las medidas tomadas por la reina

${ }^{24}$ Marqués de ForondA: «Ordenanzas de Ávila», BRAH, LXXI, 1917, 512 y ss. Cfr. J. GAUTIER DALCHE: «Les procesus de decision dans un gouvernement urbain selon les Ordonnances d'Ávile (1487)", En la España Medieval. La ciudad hispánica durante los siglos XIII al XVI. Universidad Complutense de Madrid, 6, 1985, 507-520.

${ }^{25}$ Marqués de Foronda: Obr. cit. pág. 513.

${ }^{26}$ Ibidem.

${ }^{27}$ Ibidem, pág. 318.

${ }^{28} \mathrm{Ibidem}$, pág. 515. 
Isabel quien en una carta-arancel fechada en Alcalá de Henares a 3 de marzo de 1503 dirigida a los escribanos del concejo y en otra del 7 de junio del mismo año manda «que se pague a diez maravedies cada hoja de pliego entero, escrita fielmente de buena letra cortesana y apretada e non procesada; de manera que las planas sean llenas, no dejando grandes márgenes, e que en cada plana aya, a lo menos, treinta e çinco renglones, e quinçe partes en cada renglón" ${ }^{29}$. Vemos cómo el concejo de Ávila ya había querido limitar los abusos que se pudieran cometer en este campo por parte de los escribanos y a estos demandando y consiguiendo que aquel no "cuente renglones ni partes" en las "tiras" que se empleaban para levantar acta de los autos judiciales, aunque se mantenga el precio de la «tira».

También en el capítulo de «los remates y pregones» consiguieron los escribanos mejorar los derechos a cobrar por su trabajo y en cuantía similar a lo dicho en el grupo anterior. A la postre el concejo cedió sobre todo en lo relativo a los testamentos y testimonios y sobre todo en lo relacionado con los juicios, a nuestro entender, precisamente en los aspectos que mayor interés tenían los escribanos y donde ejercerian mayor presión sobre el concejo, aunque ignoramos cuáles eran las demandas reales formuladas por el «cabildo» de los escribanos. En cualquier caso se llegó a un acuerdo favorable para éstos.

«E luego Juán de Arévalo e Juán Aluarez e Ferrando Hortega e Francisco Rodriguez e Francisco Alias por sí e en nombre del cabildo de los escriuanos públicos del número de la dicha cibdad dixeron que consentían e consistieron en los dichos capítulos» ${ }^{30}$.

Ignoramos el tiempo que pudieron durar las negociaciones entre las partes, pero no sería muy arriesgado aventurar que éstas debieron empezar al mismo tiempo que se hacían las ordenanzas a las que rectifica este acuerdo. Respecto del "cabildo" o "colegio" formado por estos escribanos cabe mencionar que el escribano que levanta acta de este acon-

${ }^{29}$ A. Millares CaRlo: Tratado de Paleografía Española, Madrid 1932 (existe reimpresión) pág.345.

${ }_{30}$ Marqués de Foronda: Obr. cit., pág. 516. Cfr. M. Cantera Montenegro, «El concejo de Logroño en tiempo de los Reyes Católicos», Hispania XLVI, 162, 1986, 27 donde se recoge otro aspecto y forma de organización de los escribanos públicos mediante "conçierto e liga e monipodio con juramento" con bolsa común y reparto de beneficios globales. 
tecimiento recoge en la primera ocasión, en la negociación, los nombres de cuatro escribanos públicos, mientras que entre los que "consienten" en el acuerdo figuran cinco; falta uno de los iniciadores del trato y aparecen dos nuevos. A tenor de este listado el cabildo lo formaban más de seis escribanos públicos del número.

\subsection{La Princesa Isabel y los escribanos de Ávila}

Ningún otro miembro de la realeza, ni rey, se ocupó expresamente de cuestiones relacionadas con los escribanos abulenses con anterioridad a la princesa Isabel, posteriormente Isabel la Católica, aunque, sin duda, intervinieran en el nombramiento de los escribanos públicos, extremo éste deducible, que no constatable, a través de la lectura de los documentos conservados.

\subsubsection{El salario de los escribanos del concejo}

El día 29 de enero de 1471, Isabel, "prinçesa de Asturias, legítima heredera e subçesora de los reinos de Castilla e de León..." escribe un diploma al concejo de Ávila dando «liçençia, autoridat e facultad al conçejo" abulense para que suba el salario a los regidores, a los mayordomos y a los escribanos del concejo ${ }^{31}$.

Comienza reconociendo que la demanda que da origen a esta decisión ha de buscarse en Ávila. No indica, sin embargo, de dónde procede la información recibida, si del concejo como tal, también atañe a los regidores, o sólo de los tres grupos que se benefician del contenido de este documento. La princesa de forma genérica dice: "yo soy çierta e ynformada» que los regidores, escribanos y mayordomos «teneis cada uno de salario, en cada un año, con los dichos ofiçios ochoçientos maravedies... pagados de las rentas de los propios del dicho conçejo" ${ }^{32}$. La fijación y permanencia de este salario era acorde con otras circunstancias económicas que nada tienen que ver con la realidad actual. Antes, a tenor de lo expuesto por la princesa, por una parte las rentas del concejo "estavan puestas a baxos precios"; de otra parte «todas las cosas valian

${ }^{31}$ AHP. Ávila. Sección Ayuntamiento. Caja 1, leg. 1, no. 4.

32 Ibidem. 
a preçios muy convenientes». Ahora «las dichas rentas han pujado en gran suma e mayor quantía que nunca valieron e todas las otras cosas han subido e estan en muy mayores presçios que solian". Este desfase ha empobrecido a los citados oficiales del concejo hasta tal punto que de mantenerse, a juicio de la princesa, «non se fallaría quién siruiese los dichos ofiçios» ${ }^{33}$.

Aunque no se puede negar el carácter económico del razonamiento expuesto por la princesa Isabel, éste no sirve más que de pantalla para sus aspiraciones políticas en general y muy en particular en la ciudad de Ávila, sede del reinado ${ }^{34}$ de su hermano Alfonso y de tensión por el poder; al mismo tiempo se reconoce la importancia política de los dos escribanos abulenses del concejo colocándolos a la misma altura de salario que a los regidores y a los mayordomos.

Ignoramos el número de años transcurridos sin que a estos oficiales del concejo se les hubieran aumentado sus salarios; debieron de ser muchos por las alusiones que se hacen a la nueva situación económica. Sabemos que los escribanos, al igual que los regidores y los mayordomos, a partir de la fecha señalada, debían de cobrar dos mil maravedies de salarios "en cada un año para siempre jamás» y cobrados «de las dichas rentas de los propios del dicho conçejo».

\subsubsection{Nombramiento de un escribano público del número}

En las referidas ordenanzas de Ávila nada se dice acerca del sistema seguido o que ha de seguirse en adelante para el nombramiento de los escribanos, tanto públicos del número como del concejo. Debía de existir, por tanto, una normativa bien consolidada y reforzada, además, por la práctica, que no dejaba lugar a la duda ni a la discusión; máxime teniendo en cuenta que se regulan, discuten y acuerdan entre partes, como hemos visto, otras cuestiones y aspectos relativos a la actividad a desarrollar por los escribanos.

${ }^{33}$ Los acontecimientos políticos acaecidos en Castilla en los años inmediatamente anteriores, incluido el encuentro de «los Toros de Guisando" con su hermano Enrique IV, obligaban a buscar los apoyos necesarios en los concejos de las villas y ciudades, y al mismo tiempo ejercer el control sobre ellos.

${ }^{34}$ M. D.-C. Morales MuñIz: Alfonso de Ávila, rey de Castilla, Institución "Gran Duque de Alba». Ávila 1988. 
Esta situación nos obliga a remontarnos a las fuentes legales de la época bajomedieval ${ }^{35}$ para situarnos en el contexto adecuado. Según estas fuentes el nombramiento de los escribanos públicos correspondía al rey 0 a aquella persona a la que el rey le concediera ese derecho ${ }^{36}$, como es el caso que nos ocupa.

La documentación que hemos estudiado confirma indirectamente que el nombramiento de los escribanos públicos, conforme a la legislación mencionada, corresponde al rey; los escribanos asi lo declaran en sus suscripciones. En este mismo sentido afirma Corral García que «en Ávila, según se deduce de la ordenanza Real de Alfonso XI de 1330 y de las Ordenanzas de 1384, el nombramiento corresponde al reys ${ }^{37}$. Este derecho se sustenta en la argumentación real de que "si fueren puestos por mano de alguno estarían más en pro de aquellos» ${ }^{38}$.

Nos estamos refiriendo a los escribanos públicos en general y no a los escribanos del concejo. Éstos, en cualquier caso, participan del carácter de aquéllos hasta tal punto que ellos mismos, cuando ejercen para el concejo, suscriben con ambos títulos para que no quede ninguna duda al respecto. Con todo no tenemos noticias acerca del sistema seguido en el nombramiento del escribano del concejo. Sabemos que algunos de los que han ejercido su oficio de escribanos del concejo abulense, con anterioridad habian sido solamente escribanos públicos del número de la ciudad ${ }^{39}$.

${ }^{35}$ Espéculo, Fuero Real y Las Partidas. Cfr. J. Bono HuERTAS: Historia del derecho notarial Español, Madrid 1979, t. I, 1, y también J. TRENCH ODENA: «Bibliografía del notariado en España (siglo xv)", Estudios Históricos y Documentos de los Archivos de Protocolos, IV Barcelona 1974, 193-237.

${ }^{36}$ Fuero Real: libr. I, tit. VIII, ley I: “onde establecemos que en las ciudades e villas mayores, que sean puestos escrivanos públicos e que sean jurados; e puestos por el rey $o$ por quien él mandare, e non por otro home". Y en similares términos se expresa el Espéculo: libr. IV, tit. XII, ley I: «Poner escivanos non conviene tanto a ningun ome como al rey. Ca él los deve poner primeramente en su casa... e él a poder de poner en las ciudades en en las villas paraq fezer los escriptos".

En cuanto a la concesión del derecho a nombrar escribanos en los señoríos por parte del Señor, cfr. F. ArRibas ArRanz: "Los escribanos públicos en Castilla en el siglo XV", Centenario de la Ley del Notariado, 1, 1964, 261, lám. 1. M. S. MARTín POStigo: La cancillería castellana de los Reyes Católicos, Valladolid 1959, págs. 306-308.

${ }^{37}$ E. Corral García: El escribano del concejo en la corona de Castilla. (Siglos XI al XVIII), Burgos 1987, pág. 13.

${ }^{38}$ lbidem, pág. 10.

${ }^{39} \mathrm{Ibidem}$, pág. 13 "Como norma los escribanos del concejo han de designarse de entre los escribanos del número como conditio sine qua nom, y ello tanto su provisión corresponda al rey, al concejo, al señor 0 al cabildo de los escribanos. No debe olvidarse 
En consonancia con la legislación recogida más arriba, la princesa Isabel (más tarde la reina Isabel, la Católica) actuando como "Señora» de la ciudad de Ávila, nombra a Pero Gutierrez escribano del número de la citada ciudad ${ }^{40}$. Este nombramiento se realiza previa renuncia y solicitud firmada por el padre del beneficiado y a petición de "algunos» regidores del concejo. Una vez que el concejo reciba el juramento «que en tal caso se requiere", podrá usar del signo que la princesa ha determinado y ejercer el oficio de escribano, salvo "sy soys o fuerdes clerigo coronado» ${ }^{41}$.

La toma de posesión del cargo se desarrolla de la siguiente manera. Después de unos meses, el aspirante se presenta ante el concejo con la carta de nombramiento y pide que se le reciba como escribano público de la ciudad. El concejo acepta el nombramiento y la solicitud y manda a «Ferrando Sánchez de Pareja, escrivano público de la dicha çibdad a merçed de nuestra señora la prinçesa e escribano de los fechos del dicho conçejo... que resciviese del dicho Pero Gutiérrez el juramento que en tal caso se requiere ${ }^{42}$. Una vez realizado el juramento, el concejo le admitió como escribano público del número «para en toda su vida».

Cabe señalar aún alguna circunstancia. No encontramos en todo el proceso ninguna mención a una posible selección entre varias personas aspirantes al oficio. Se destaca la participación de miembros del concejo en la propuesta, que no en el nombramiento y la del escribano del concejo en la toma de posesión. En este último acto se indica que Pero Gutiérrez es "veçino de la dicha ciudad de Avila», aspecto este de la vecindad que se recoge en la legislación ya mencionada como conditio sine qua nom para acceder al oficio de escribano público.

\footnotetext{
el matiz concejil que progresivamente va adquiriendo el oficio, lo que propicia en su elección la intromisión de los concejos".

${ }^{40}$ AMA. Sección Históricos. leg. 1, fols. 1-2. La vemos actuar igualmente como "Señora" cuando sube el sueldo a los regidores, mayordomos y escribanos del concejo abulense (AHP. Avila. Sección Ayuntamiento. Caja 1, leg. 1, non. 4) o cuando nombra al corregidor (AMA. Sección Históricos, leg.1).

${ }^{41}$ AMA. Sección Históricos. leg. 1, fols. 1-2. E. Corral Garcia, Obr. cit., pág. 24 dice que "en Castilla, en la Baja Edad Media, las Cortes de Madrid de 1419 piden a Juan II que las personas coronadas no ocupen 'oficios seglares" en ciudades y villas "porque el rey no les puede castigar".

${ }_{42}$ AMA. Sección Históricos. leg. 1.
} 